Rev. Adm. Saúde (On-line), São Paulo, v. 21, n. 82: e278, jan. - mar. 2021, Epub 24 mar. 2021 http://dx.doi.org/10.23973/ras.82.278

PERSPECTIVAS

\title{
Acreditação hospitalar e o enfrentamento ao covid-19
}

Hospital accreditation and coping with covid-19

\section{Humberto de Moraes Novaes ${ }^{1}$}

1. Médico, especialista em administração hospitalar e de sistemas de saúde. Ex-consultor da Organização Pan-Americana da Saúde e ex-coordenador da implementação de programas de acreditação de hospitais na região. Ex-diretor executivo do Instituto Central e do Instituto do Coração do Hospital das Clínicas da Faculdade de Medicina da Universidade de São Paulo (HCFMUSP). Cofundador do Programa de Estudos Avançados em Administração Hospitalar e de Sistemas de Saúde do HCFMUSP

\section{RESUMO}

Esta resenha histórica pretende recordar os desafios para implementar qualidade na assistência nos hospitais brasileiros. Várias iniciativas foram propostas nos últimos 30 anos, mas a realidade atual ainda demonstra a grande necessidade de que muitas ações se têm por fazer. Esperamos que o alerta trazido pelo coronavírus possa estimular as mudanças necessárias para estas transformações.

Palavras-chave: Gestão de qualidade em saúde; Acreditação hospitalar; Pandemia pelo novo coronavíruis (2019-nCoV)

\section{ABSTRACT}

This historical review intends to recall the challenges to implement quality of care in Brazilian hospitals. Several initiatives have been proposed in the past 30 
years, but the current reality still demonstrates the great need for many actions to be done. We hope that the alert brought by the coronavirus can stimulate the necessary changes for these transformations.

Keywords: Quality Management; Hospital accreditation; New Coronavirus Pandemic (2019-nCoV)

Os hospitais, independentemente de serem públicos ou privados, devem estar preparados para enfrentar crises de qualquer natureza, sejam situações de graves acidentes, explosões com vítimas fatais ou enfrentamentos violentos entre grupos extremistas. A grande maioria destes acidentes chega as emergências hospitalares, assim como vítimas de epidemias, como as do covid-19.

Manter seus diversos serviços aos seus pacientes segundo protocolos, estabelecidos por suas respectivas entidades cientificas específicas; normas estabelecidas, regras e auditorias constantes, entre outras atividades, são princípios inerentes da "acreditação hospitalar". Numa época em que o país enfrenta uma terrível pandemia seria útil recordar os esforços feitos nos últimos anos para melhoria da atenção médica no Brasil pela Organização PanAmericana da Saúde (OPAS).

Nos fins dos anos 80 havia algumas iniciativas de avaliação da qualidade hospitalar que estavam sendo desenvolvidas. A primeira, em São Paulo, promovida pela Associação Paulista de Medicina (APM) e o Conselho Regional de Medicina (1); a segunda, no Rio Grande do Sul, sob a liderança do setor privado, através da sua Associação de Hospitais; a terceira, no Estado do Paraná, estimulada pela Secretaria Estadual de Saúde e a quarta, no Rio de Janeiro, em um acordo entre a Academia Nacional de Medicina, o Colégio Brasileiro de Cirurgiões e o Instituto de Medicina Social (UERJ).

Nos anos 90, a Organização Pan-Americana da Saúde, repartição para América Latina e Caribe da Organização Mundial da Saúde, sediada em Washington D.C., mantinha e mantem até hoje uma estreita relação formal com os ministérios da saúde de todos os países desta região. Estes ministérios relacionavam-se raramente com os hospitais privados naquela ocasião.

Conscientes da necessidade de desenvolver assessoria aos hospitais, não somente aos públicos, mas também aos privados, a OPAS firmou um acordo, em 1986, de cooperação técnica com a Federação Latino-Americana de Hospitais, membro permanente do Conselho Diretor da OPAS, para contornar o obstáculo desta resistência dos ministérios com o setor hospitalar privado, e assim poderíamos oferecer consultoria também a estes hospitais (2). 
Pretendíamos com este acordo ter mais flexibilidade para introduzir a metodologia de acreditação hospitalar na região, para todos os hospitais públicos, mas também com compromisso de trabalhar, pela primeira vez com hospitais privados. A metodologia da acreditação era completamente desconhecida e a maioria dos administradores hospitalares desconheciam até a palavra "acreditação".

Nesta mesma ocasião, fizemos um levantamento de 15.000 hospitais da América Latina e de suas características principais (3). Identificamos que $70 \%$ tinham menos de 70 leitos para internação, era critica a situação de recursos humanos, baixa resolubilidade clínica, falta de mecanismos de controle, mínima prevenção de infecção hospitalar, ausência de comissões de qualidade, insuficiente capacitação, e inconsistente avaliação dos custos operacionais. Esta situação continua em grande parte em vários hospitais, como pudemos constatar durante esta terrível pandemia.

A introdução progressiva de padrões de qualidade institucionais através da acreditação poderia ajudar a reverter esta situação, principalmente em hospitais públicos. A ausência destes princípios tem revelado nos últimos 12 meses, situações críticas em muitos hospitais com os pacientes portadores do coronavírus.

Se bem que existem grandes centros médicos públicos ou privados, comparáveis aos mais avançados de qualquer outro continente, uma quantidade razoável destes nosocômios não resistiria uma mínima avaliação para garantir uma qualidade permanente em todos seus serviços. Frente a este cenário, a OPAS/OMS, desenvolveu um modelo de acreditação hospitalar apropriado as características desta região, suficientemente flexível, de maneira a adaptar-se as pronunciadas diferenças entre uma sub-região e outra, para ser amplamente discutido entre os países.

A acreditação é um método que desenvolve padrões de avaliação para a melhoria contínua da qualidade do atendimento aos pacientes e do desempenho organizacional, oferecendo

confiança da comunidade no seu hospital. O passo inicial deveria ser o estabelecimento de padrões de qualidade que pudessem servir de referência para os avaliadores destes processos:

- $\quad$ Os padrões deveriam ser específicos para cada unidade ou setor hospitalar (laboratório, centro cirúrgico, lavanderia etc.);

- $\quad$ Ser de complexidade crescente, ou seja, haveria padrões mínimos, nível 1, para serviços hospitalares, seguidos de padrões mais diferenciados e, finalmente, os padrões finais que dariam aos hospitais condições de excelência;

- $\quad$ Os padrões mínimos já seriam suficientes para oferecer uma assistência de qualidade e os progressivos padrões de nível mais alto seriam para estimular os hospitais a avançarem a melhores $\mathrm{e}$ mais sofisticados métodos de atenção aos pacientes; 
- Comprovação da existência ou ausência destes padrões, através de "indicadores", seriam observados por uma comissão de peritos avaliadores.

Este modelo de Manual de Acreditação para América Latina e Caribe da OPAS, cobria todos os serviços de um hospital geral, para tratamento de casos agudos. Sua redação teve por objetivo o não estabelecimento de paradigmas, mas sim de um guia, para servir de ilustração as comissões institucionais nacionais quando elaborarem seus próprios instrumentos de avaliação.

Para cada serviço hospitalar foram estabelecidos "padrões", ou seja, o nível de atenção, prática ou método ótimo esperado, definido por peritos e/ou associações de profissionais. Em cada situação, o padrão inicial seria o limite mínimo de qualidade exigido. Esperava-se que nenhum hospital de algum país, que estivesse em um processo de acreditação, se situasse abaixo deste nível, dentro de um período de 2 anos, por exemplo. À medida que estes padrões iniciais fossem alcançados, o hospital deveria procurar perseguir o padrão seguinte, ou seja, quando o padrão de nível 1 é atingido, o passo seguinte e alcançar os níveis 2 ou 3 sucessivamente.

As recomendações do programa da OPAS para acreditação era de que não se "acredita" um serviço isolado. Mesmo que uma unidade do hospital esteja plenamente montada e de qualidade excepcional, com níveis de sofisticação nível 3, por exemplo, a instituição continuaria como acreditada no primeiro nível, se os outros serviços não passaram além do primeiro escalão.

Esta metodologia teve por objetivo reforçar o fato de que as estruturas e processos do hospital são de tal ordem interligados, que o mal funcionamento de um componente interfere em todo o conjunto e no resultado global. Assim, o hospital "é" ou "não é" acreditado. Não se estabelecem níveis de acreditação distintos para cada um dos serviços. É comum encontrarmos hospitais que estão realizando sofisticados procedimentos clínicos, porém, por exemplo, o centro cirúrgico tem que interromper suas atividades por falta de insumos; ou os serviços hospitalares são considerados bons, porém a logística da farmácia deixa muito a desejar.

A acreditação e um método de consenso, racionalização e ordenamento do hospital. 0 primeiro instrumento de avaliação técnica, explícita, objetiva da qualidade, e como já mencionamos, o próprio Manual de Acreditação. $O$ segundo, é a comissão ou órgão institucional de acreditação, que deverá ser apolítica, multirrepresentativa, realizando sua tarefa silenciosa e periodicamente.

Quando esta comissão está sob a exclusiva tutela governamental sofre frequentes distorções, devido as inúmeras pressões políticas que são submetidos os governantes, e em consequência os hospitais, ou não são corretamente submetidos ao processo de acreditação, ou não se tomam as medidas corretivas aconselhadas pela comissão de acreditação.

O perfil dos avaliadores se concentra naqueles profissionais de indiscutível experiência em administração de hospitais, já que se necessitam indivíduos 
com estas características pessoais para realizar recomendações pertinentes e assessorar na melhora de funcionamento dos hospitais. A acreditação é sempre periódica, confidencial, com estabelecimento de prazos para correção das falhas encontradas. A acreditação é, na realidade, um procedimento de educação contínua da gerência hospitalar.

O Brasil foi um dos países mais complexos para implementação devido as dificuldades de acesso a informações e o grande número de hospitais. O país tem aproximadamente a metade dos hospitais da América Latina e Caribe. As características das instituições desta região da OPAS, possuem estruturas funcionais bem semelhantes as nossas, com relação aos aspectos da qualidade da assistência nestes países.

O manual produzido pela OPAS foi apresentado a representantes de instituições públicas e privadas do Brasil em conferências internacionais em Brasília. Foram convidados consultores representantes de cada um dos programas estaduais em fase de estudos para testar o manual. Poucos avanços se puderam observar após três décadas (4).

A estratégia da OPAS foi contratar alguma entidade que tivesse ligação com nossa associada, a Federação Latino-Americana de Hospitais, no caso a Federação Brasileira de Hospitais. O objetivo seria de que os hospitais começassem a ter acesso a alguma informação sobre uma metodologia que, na época, desconheciam completamente.

A primeira versão de padrões do manual da OPAS foi aplicada para testes em hospitais, de diferentes categorias, e em distintos estados do país. Finalmente, em 1999, foi apresentado o Manual de Acreditação de Hospitais do Brasil (5).

Neste processo, o papel de um corpo de enfermeiros comprometido com o programa de acreditação é fundamental, pois são de todos os que trabalham nos hospitais, a enfermagem é o grupo profissional com presença permanente, familiarizado durante e depois da formação acadêmica com temas gerenciais e de auditoria clínica, com as habilidades ímpares para assessorar a implementação e monitoria de todo o processo de acreditação.

A nova entidade proposta pela OPAS seria representada por uma junta de diretores compondo três categorias gerais:

- Representantes de associações, federações e organismos similares responsáveis pelos hospitais particulares, universitários, filantrópicos ou religiosos;

- Representantes de organizações de medicina de grupo, companhias de seguro, cooperativas médicas e outras do setor privado;

- Representantes do setor público, incluindo o Ministério da Saúde, secretarias estaduais e municipais de saúde.

Os membros fundadores recomendados pela OPAS seriam representantes de organizações, tais como: 
- $\quad$ Associação Brasileira de Hospitais Universitários;

- $\quad$ Confederação Nacional de Saúde;

- $\quad$ Federação Brasileira de Hospitais;

- $\quad$ Associação Brasileira de Medicina de Grupo;

- $\quad$ Associação Brasileira de Autogestão em Saúde;

- $\quad$ Federação Nacional de Seguros Privados e Capitalização;

- $\quad$ Conselho Nacional de Secretarias Estaduais de Saúde;

- $\quad$ Confederação das UNIMED.

\section{Conclusão}

É evidente que a implementação de iniciativas, como as propostas pela OPAS, a APM e outras instituições, não é uma barreira eficaz para bloquear o pandemônio causado pela disseminação mundial do covid-19. Entretanto, a existência de padrões de qualidade, regras claras para logística de insumos, e reciclagem, com atualizações periódicas, dos profissionais da saúde, auxiliaria para aliviar o fardo e o colapso caótico de alguns hospitais, como acontece em Manaus, na Região Norte, ou em Araraquara, SP.

Existe uma diferença fundamental entre o processo de implementação de programas de acreditação nos Estados Unidos e no Brasil. Nos EUA, após as experiências iniciais do Colégio Americano de Cirurgiões, com sua proposta de "padrões mínimos para hospitais" revelou, em 1918, que dos 692 hospitais visitados somente 89 atendiam os requerimentos destes padrões mínimos.

Pouco a pouco, os hospitais foram sendo submetidos a estas avaliações pelo colégio e, em 1950, já havia 3.200 aprovados. Nesta ocasião, o Colégio Americano de Clínica Médica, a Associação Americana de Hospitais, a Associação Médica Americana e a Associação Médica do Canadá se juntaram ao Colégio de Cirurgiões para fundar a Comissão Conjunta de Acreditação de Hospitais, organização independente do governo, sem fins de lucro, cujo propósito principal era oferecer uma "acreditação" voluntária.

Com o decorrer dos anos a característica "voluntária" passou a ter um significado muito relativo, já que os hospitais dos EUA necessitam dos reembolsos de pacientes pertencentes à seguridade social, Medicare e Medicaid (o SUS americano). Tratam de programas específicos para pacientes pobres ou idosos, já que estes representam grande parte do orçamento hospitalar. Somente são autorizados a receber o reembolso federal se o hospital é acreditado pela Comissão Conjunta conforme Lei Federal. Em 1972, o Ministério da Saúde dos EUA confirmou a Comissão Conjunta (JCHAO) como sua representante na certificação de hospitais do país até hoje. 
Durante os seus mais de 70 anos, a Comissão Conjunta foi evoluindo, incorporando no processo de acreditação outros serviços de saúde, além dos hospitais, como acreditação de instituições para doentes crônicos, estabelecimentos para doentes mentais, assistência domiciliar, laboratórios, redes de serviços, cirurgia ambulatorial, farmácias, entre outros estabelecimentos acreditados.

A grande diferença é que o SUS não exige que os hospitais sejam "acreditados" e assim continuam relativamente poucos os hospitais acreditados quando comparados com o universo hospitalar brasileiro. Ainda não há disposição política de implementar a obrigatoriedade de que para receber recursos do SUS que o hospital necessita ser acreditado, como acontece nos EUA. Enquanto estas iniciativas não acontecerem continuaremos assistindo hospitais executarem atividades com mínima qualidade com o aumento do número de óbitos por coronavírus, sem significativas melhoras da vida dos que sobrevivem.

O enorme problema que as instituições públicas no Brasil enfrentam são as dificuldades encontradas no seu financiamento. Existe há anos uma resistência ideológica de profissionais da saúde para que os hospitais públicos recebam pacientes particulares ou de seguradoras, já que estes ingressos monetários dariam fôlego a estes nosocômios respirarem com mais folga. Existem algumas exceções e pode ser mencionada uma, por exemplo, o Hospital das Clínicas da Faculdade de Medicina da Universidade de São Paulo que apresenta condições especiais de atenção médica e é considerado por muitos como o maior e melhor hospital da América Latina para pacientes do SUS e privados.

A implementação do processo de acreditação aos hospitais brasileiros daria a população a segurança de uma atenção médica de qualidade. Porém, infelizmente, a realidade é a inexpressiva quantidade de hospitais brasileiros acreditados, como bem ficou demonstrado durante esta pandemia, que levou ao conhecimento geral da sociedade da penosa situação de muitas enfermarias ou UTIs.

\section{Nota do autor}

No período entre 1989 e 1995 a OPAS investiu consideráveis recursos com a iniciativa de acreditação de hospitais em, praticamente, todos países da América Latina e Caribe. Foram contratados renomados consultores locais, realizadas reuniões nacionais e conferências internacionais. Em uma destas últimas conferências, na sede da OPAS em Washington, foi apresentado aos representantes dos países o Manual de Acreditação.

Foi estimulada a criação nos países de comissões nacionais de acreditação. Vários países adaptaram o manual para suas realidades.

Durante as últimas décadas, entretanto, estas iniciativas foram se esvaindo e no momento nenhum país da região utiliza modelos de acreditação para a maioria dos seus hospitais, com exceção dos Estados Unidos e Canadá. 


\section{REFERÊNCIAS}

1. Burmester H. Experiências da Associação Paulista de Medicina e Conselho Regional de Medicina. Seminário sobre Acreditação dos Serviços de Saúde como Instrumento de Controle da Qualidade da Organização Pan-Americana de Saúde/Federação Brasileira de Hospitais; abril 1992.

2. Paganini JM, Novaes HM. La Garantía de Calidad - Acreditación de Hospitales para América Latina y el Caribe. Series Desarrollo y Fortalecimiento de los Sistemas Locales de Salud - SILOS № 13, 190p. Washington D.C.: Organización Panamericana de la Salud; 1992.

3. Organización Panamericana de la Salud. Caderno Especial. Directorio Latino Americano y del Caribe de Hospitales. Washington D.C.: Organización Panamericana de la Salud; 1996.

4. Novaes HM. Garantia de Qualidade em Hospitais da América Latina e do Caribe. EM: Acreditação de Hospitais para América Latina e o Caribe. Organização Pan-Americana da Saúde/ Organização Mundial da Saúde - Federação Latino-Americana de Hospitais - Série SILOS n 13. Brasília: Federação Brasileira de Hospitais; 1992.

5. Novaes H. Implantación de Programas de Garantía de Calidad en los Hospitales de América Latina y el Caribe (Implementação de Programas de Garantia de Qualidade em Hospitais na América Latina e no Caribe). Rev. Educ. Med. y Salud. 1993; 27(3):31-38.

Recebido: 23 de fevereiro de 2021. Aceito: 24 de março de 2021

Correspondência: Humberto de Moraes Novaes. E-mail: ras@apm.org.br

Conflito de Interesses: o autor declarara não haver conflito de interesses. 